\title{
Facility assessment and qualitative analysis of health worker perspectives on neonatal health in Malawi
}

\author{
Mai-Lei Woo Kinshella ${ }^{1 *} \mathbb{0}$, Alinane Linda Nyondo-Mipando², Queen Dube 3 , David M. Goldfarb ${ }^{4}$ and \\ Kondwani Kawaza ${ }^{5}$
}

\begin{abstract}
Objectives: The "Integrating a neonatal healthcare package for Malawi" (IMCHA\#108030) project conducted mixedmethods to understand facility-based implementation factors for newborn health innovations in low-resourced health settings. The objective of the two datasets was to evaluate: (a) capacity of quality newborn care in three districts in southern Malawi, and (b) barriers and facilitators the scale up of bubble continuous positive airway pressure (CPAP), a newborn health innovation to support babies with respiratory distress.

Data description: The Integrated Maternal, Neonatal and Child Quality of Care Assessment and Improvement Tool (version April-2014) is a standardized facility assessment tool developed by the World Health Organization (WHO) that examines quality as well as quantity and availability. The facility survey is complemented by a qualitative dataset of illustrative quotes from health service providers and supervisors on bubble CPAP implementation factors. Research was conducted in one primary health centre (facility assessment only), three district-level hospitals (both) and a tertiary hospital (qualitative only) in southern Malawi. These datasets may be used by other researchers for insights into health systems of low-income countries and implementation factors for the roll-out of neonatal health innovations as well as to frame future research questions or preliminary exploratory research on similar topics.
\end{abstract}

Keywords: Facility assessment, Qualitative research, Newborn care, Bubble continuous positive airway pressure (CPAP), Health worker perspectives, Malawi

\section{Objective}

Neonatal mortality has become an increasingly important contributor to overall global child mortality and is now estimated to be over $45 \%$ of all under- 5 mortalities [1]. In Africa alone, it is estimated that approximately 1 million babies per year die in their first 4 weeks of life [2]. Though Malawi, a small land-locked country in subSaharan Africa, is celebrated for achieving the Millennium Development Goals of reducing under-5 mortality

\footnotetext{
*Correspondence: maggie.kinshella@cw.bc.ca

${ }^{1}$ Department of Obstetrics and Gynaecology, BC Children's and Women's

Hospital and University of British Columbia, Vancouver, Canada

Full list of author information is available at the end of the article
}

by two-thirds, neonatal mortality rates remain high with latest estimates of 20 per 1000 live births, equating to 12,000 neonatal deaths in 2019 alone [3]. Malawi has an estimated preterm birth rate of $10.5 \%$ [4] and approximately $35 \%$ of neonatal deaths are attributed to preterm birth, making prematurity the leading direct cause of neonatal mortality [1]. Preterm infants pose particular challenges; they are especially vulnerable to feeding difficulties because their sucking and swallowing reflexes are immature, they develop breathing problems and have body temperature instability $[5,6]$.

In this project, we conducted mixed-methods research to understand how best to scale up essential life-saving neonatal interventions at the district-level in the

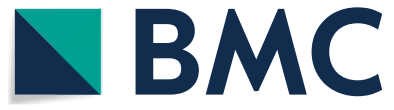

(c) The Author(s) 2021. This article is licensed under a Creative Commons Attribution 4.0 International License, which permits use, sharing, adaptation, distribution and reproduction in any medium or format, as long as you give appropriate credit to the original author(s) and the source, provide a link to the Creative Commons licence, and indicate if changes were made. The images or other third party material in this article are included in the article's Creative Commons licence, unless indicated otherwise in a credit line to the material. If material is not included in the article's Creative Commons licence and your intended use is not permitted by statutory regulation or exceeds the permitted use, you will need to obtain permission directly from the copyright holder. To view a copy of this licence, visit http://creativeco mmons.org/licenses/by/4.0/. The Creative Commons Public Domain Dedication waiver (http://creativecommons.org/publicdomain/ zero/1.0/) applies to the data made available in this article, unless otherwise stated in a credit line to the data. 
Malawian context. The database includes a comprehensive facility survey for newborn care adapted from the World Health Organization (WHO) Integrated Maternal, Neonatal and Child Quality of Care Assessment and Improvement Tool (version-April-2014). The database also includes qualitative analyses of health worker perspectives on barriers and facilitators to implementing bubble continuous positive airway pressure (CPAP). Research was conducted in one primary health centre (facility assessment only), three district-level hospitals (both) and a tertiary hospital (qualitative only). The three district-level hospitals have coded numeric identifiers to link between the facility survey and qualitative datasets. An assessment of the quality of newborn care at district hospitals in Malawi was published from the facility survey dataset [7] and the qualitative dataset was used to understand perspectives of health workers on barriers and enablers of implementing bubble CPAP [8] and factors affecting caregiver engagement with bubble CPAP [9]. These datasets would be of value to researchers seeking to strengthen newborn care in other low resource settings. Connections between qualitative and quantitative datasets may lead to novel insights into factors that impact scaling up innovations.

\section{Data description}

This research was collected as part of the "Integrating a neonatal healthcare package for Malawi" (IMCHA \#108030), part of the Innovating for Maternal and Child Health in Africa (IMCHA) initiative.

Using the WHO Integrated Maternal, Neonatal and Child Quality of Care Assessment and Improvement Tool (version April-2014), the facility surveys were conducted health facilities providing secondary-level care in three districts in southern Malawi in November 2017. There were government hospitals in two districts and a private not-for-profit mission hospital alongside a public primary health centre that provided some secondary level services in the third district. The assessment tool was not modified for the primary health centre, though some inpatient services were skipped when it was not provided. Assessments in all facilities were conducted by trained data collectors, which involved observations of practices and resource availability as well as interviewing relevant health professionals, such as the nurse-in-charge of the ward and laboratory technicians (Additional file 1).

This study focuses only on neonatal care and includes the modules on infrastructure, neonatal care and maternal care related to labour and delivery. Using a series of structured checklists, each aspect of care was observed and scored 1-5. A score of five indicated good practice complying with WHO standards of care, a score of four indicated minor need for improvement, a score of three indicated some need for improvement, a score of two indicated considerable need and a score of one indicated totally inadequate care or a potentially life-threatening practice. Variables assessed included infrastructure, ward layout, organisation of care including staffing, emergency care, in patient care, infection control and supportive care, essential drugs, equipment and supplies, case management, and monitoring and follow up. Dimensions of the dataset are by facility described by type and linked with the qualitative dataset by coded identifier (District 1-government hospital, District 2-mission hospital, District 3-government hospital). With over 600 questions, the resulting data are a comprehensive evaluation of the capacity for neonatal care available in 2016 at secondarylevel care facilities in rural southern Malawi. The resulting data are largely quantitative, with some open-text comments to qualify numbered responses. This survey used modules that dealt specifically with neonates from the WHO Integrated Maternal, Neonatal and Child Quality of Care Assessment and Improvement Tool and can be compared with other studies using the same tool.

The semi-structured interviews were conducted in June to August 2018. Face-to-face interviews were conducted by trained Malawian researchers at health facilities with 46 health workers. These included nurses, clinical officers, district health management (district health officer, district medical officer and district nursing officer), pediatric consultants and registrars. The qualitative dataset of health worker perspectives on barriers and facilitators to implementation of bubble CPAP includes the following variables: training and staffing, initiation, monitoring, weaning, caregivers and supplies and equipment. Dimensions of the dataset are by facility type and health worker cadre. Quotes include detail on the sex of the respondent and age ( $\mathrm{F}$ for female, $\mathrm{M}$ for male and number for age). Health facility numbering (District 1 -government hospital, District 2-mission hospital, District 3-government hospital) will be the same as in the facility survey to provide a link between the two datasets in this database. In addition, a tertiary-level hospital (Central hospital) is also included in the qualitative dataset. This data could be used by other researchers to understand barriers and facilitators to implementing innovative technologies in resource constrained settings and as a baseline for the scale up of neonatal care packages in Malawi (Table 1).

\section{Limitations}

To maintain participant's privacy and prevent sharing identifying information, qualitative data are presented coded to general topic areas rather than raw transcripts. Quotes have been reviewed for identifying information and place names replaced by their facility type, participants are aggregated to their overall medical cadre 
Table 1 Overview of data files/data sets

\begin{tabular}{llll}
\hline Label & Name of data file/data set & File types (file extension) & Data repository and identifier (DOI or accession number) \\
\hline Data file 1 & Detailed description of methodology & MS word file (.docx) & figshare (https://doi.org/10.6084/m9.figshare.12380480) [10] \\
Data set 1 & Facility assessment.xlsx & MS Excel file (.xlsx) & figshare (https://doi.org/10.6084/m9.figshare.12380480) [10] \\
Data set 2 & Qualitative dataset.csv & MS Excel file (.csv) & figshare (https://doi.org/10.6084/m9.figshare.12380480) [10] \\
\hline
\end{tabular}

category instead of specific positions and study sites are numbered instead of named. Consequently, qualitative responses are grouped as "nurses", which includes nursing officer, senior nurses, registered nurses and nurse technicians, and "district health management" includes district health officer, district medical officer and district nursing officer to protect confidentiality.

\section{Abbreviations}

CPAP: Continuous positive airway pressure; IMCHA: Innovating for Maternal and Child Health in Africa initiative; WHO: World Health Organization.

\section{Supplementary Information}

The online version contains supplementary material available at https://doi. org/10.1186/s13104-021-05679-5.

Additional file 1: Table S1. Structure of the full WHO Integrated Maternal, Neonatal and Child Quality of Care Assessment and Improvement Tool. Table S2. Areas of care assessed by the adapted WHO integrated quality of care assessment tool. Table S3. Study site characteristics.

\section{Acknowledgements}

This manuscript is part of the "Integrating a neonatal healthcare package for Malawi" project within the Innovating for Maternal and Child Health in Africa (IMCHA) initiative. The authors would like to express their gratitude to the IMCHA team for their support, especially Sangwani Salimu (qualitative research coordinator), Mwai Banda (project manager based at College of Medicine, Malawi), Michelle Dittrick (project manager based at the University of British Columbia, Canada) and Marianne Vidler (PRE-EMPT program manager at the University of British Columbia, Canada). We are grateful to all the study participants that participated in the study and the nurses who helped in data collection. We are thankful for the institutional support from the hospitals for allowing us to conduct the study in their facilities and support from the Centre for International Child Health $(\mathrm{CICH})$ based at BC Children's Hospital in Canada, the International Development Research Centre (IDRC) based in Canada and the Data Curation Centre in the UK.

\section{Authors' contributions}

MWK drafted the original paper and coordinated the feedback to revise the paper. ALNM, QD, DMG and KK contributed to the conceptualization of the research project and its funding acquisition and critically reviewed all versions. KK supervised the facility survey component of the research project and oversaw methodology, investigation, data analysis and write-up as well as supervised the entire project overall and contributed to the interpretation of the data. ALNM supervised the qualitative component of the research project and oversaw methodology, investigation, data analysis and write-up. All authors contributed to the interpretation of the data. All authors read and approved the final manuscript.

\section{Funding}

This manuscript is supported by the IMCHA grant (\#108030) and the IDRC Open Research Data Initiative (\#109059-008).

\section{Availability of data and materials}

The data described in this Data note can be freely and openly accessed on the figshare repository https://doi.org/10.6084/m9.figshare.12380480. Please see Table 1 and reference [8] for details and links to the data.

\section{Declarations}

\section{Ethics approval and consent to participate}

Ethics approvals were obtained from the University of Malawi College of Medicine (P.08/15/1783) and the University of British Columbia (H15-01463-A003). All hospitals provided institutional support for the study to be conducted in their facilities. All participants provided a written informed consent prior to study participation.

\section{Consent for publication}

Not applicable.

\section{Competing interests}

The authors declare that they have no competing interests.

\section{Author details}

'Department of Obstetrics and Gynaecology, BC Children's and Women's Hospital and University of British Columbia, Vancouver, Canada. ${ }^{2}$ Department of Health Systems and Policy, School of Public Health and Family Medicine, College of Medicine, University of Malawi, Blantyre, Malawi. ${ }^{3}$ Pediatrics, Queen Elizabeth Central Hospital, Blantyre, Malawi. ${ }^{4}$ Department of Pathology and Laboratory Medicine, BC Children's and Women's Hospital and University of British Columbia, Vancouver, Canada. ${ }^{5}$ Department of Pediatrics and Child Health, College of Medicine, University of Malawi, Blantyre, Malawi.

Received: 13 October 2020 Accepted: 30 June 2021

Published online: 12 July 2021

\section{References}

1. Liu L, Oza S, Hogan D, Chu Y, Perin J, Zhu J, et al. Global, regional, and national causes of under-5 mortality in 2000-15: an updated systematic analysis with implications for the Sustainable Development Goals. Lancet. 2016;388(10063):3027-35.

2. Lawn JE, Kerber K, Enweronu-Laryea C, Cousens S. 3.6 million neonatal deaths - what is progressing and what is not? Semin Perinatol. 2010;34(6):371-86.

3. Sharrow D, Hug L, Liu Y, You D. Levels and trends in child mortality: report 2020. New York: UNICEF; 2020

4. Chawanpaiboon S, Vogel JP, Moller AB, Lumbiganon P, Petzold M, Hogan D, et al. Global, regional, and national estimates of levels of preterm birth in 2014: a systematic review and modelling analysis. Lancet Glob Heal. 2019:7(1):e37-46.

5. Behrman RE, Butler AS. Preterm birth: causes, consequences and prevention. Washington: National Academies Press; 2007.

6. Lawn JE, Davidge R, Paul VK, von Xylander S, de Graft JJ, Costello A, et al. Born too soon: care for the preterm baby. Reprod Health. 2013;10(Suppl 1):S5

7. Kawaza K, Kinshella MLW, Hiwa T, Njirammadzi J, Banda M, Vidler M, et al. Assessing quality of newborn care at district facilities in Malawi. BMC Health Serv Res. 2020;20(1):227. 
8. Nyondo-Mipando AL, Kinshella MLW, Bohne C, Suwedi-Kapesa LC, Salimu $\mathrm{S}$, Banda $\mathrm{M}$, Ameh CA, et al. Barriers and enablers of implementing bubble continuous positive airway pressure (CPAP): perspectives of health professionals in Malawi. PLoS ONE. 2020;15(2):e0228915.

9. Salimu S, Kinshella MLW, Vidler M, Banda M, Newberry L, Dube Q, et al, Health workers' views on factors affecting caregiver engagement with bubble CPAP. BMC Pediatr. 2020;20(1):180.

10. Kinshella MW, Nyondo-Mipando AL, Dube Q, Goldfarb D, Kawaza K. Facility assessment and qualitative analysis of health worker perspectives on the use of bubble continuous positive airway pressure for neonatal health in Malawi. figshare https://doi.org/10.6084/m9.figshare.12380480. 2020.

\section{Publisher's Note}

Springer Nature remains neutral with regard to jurisdictional claims in published maps and institutional affiliations.
Ready to submit your research? Choose BMC and benefit from:

- fast, convenient online submission

- thorough peer review by experienced researchers in your field

- rapid publication on acceptance

- support for research data, including large and complex data types

- gold Open Access which fosters wider collaboration and increased citations

- maximum visibility for your research: over 100M website views per year

At BMC, research is always in progress.

Learn more biomedcentral.com/submissions 